\begin{tabular}{|l|l|l|}
\hline \multicolumn{2}{|c|}{ PublisherInfo } \\
\hline \hline PublisherName & $:$ & BioMed Central \\
\hline \hline PublisherLocation & $:$ & London \\
\hline \hline PublisherImprintName & $:$ & BioMed Central \\
\hline \hline
\end{tabular}

\title{
BiPAP and the relief of CHF symptoms
}

\begin{tabular}{|l|l|l||}
\hline \multicolumn{2}{|c|}{ ArticleInfo } \\
\hline \hline ArticleID & $:$ & 4148 \\
\hline \hline ArticleDOI & $:$ & $10.1186 /$ ccf-2001-3003 \\
\hline \hline ArticleCitationID & $:$ & 3003 \\
\hline \hline ArticleSequenceNumber & $:$ & 85 \\
\hline \hline ArticleCategory & $:$ & Paper Report \\
\hline ArticleFirstPage & $:$ & 1 \\
\hline \hline ArticleLastPage & $:$ & 3 \\
\hline \hline & & RegistrationDate : 2001-2-21 \\
\hline ArticleHistory & $:$ & OnlineDate \\
\hline \hline ArticleCopyright & $:$ & Biomed Central Ltd2001-2-21 \\
\hline \hline ArticleGrants & $:$ & \\
\hline \hline ArticleContext & $:$ & 130541111 \\
\hline \hline
\end{tabular}


Aff1 Christiana Hospital, Wilmington, DE, USA

\section{Keywords}

BiPAP, CHF, echocardiogram

\section{Comments}

BiPAP is often used as a means to support ventilation in episodes of respiratory distress, especially during CHF. It is often observed that successful application results in decreased respiratory effort, improved gas exchange, and avoidance of intubation. This study used echocardiography to demonstrate that even a brief application of BiPAP results in favorable hemodynamic changes, including increased cardiac output. Of particular interest is that these changes are present to a small degree after BiPAP is discontinued. Although favorable changes tend toward baseline, it suggests the possibility that longer periods of BiPAP may result in more prolonged improvements in hemodynamics, and perhaps provide relief to CHF symptoms.

\section{Introduction}

In CHF, there are three goals to ventilatory support: to improve oxygenation; to decrease work of breathing; and to improve left ventricular function. BiPAP is a commonly used form of respiratory support in CHF. This study uses echocardiography to study hemodynamic effects of BiPAP in patients with depressed cardiac function.

\section{Methods}

. Of the 18 patients who volunteered, 14 tolerated BiPAP and completed the study

. Patients were used as their own control. All data were calculated as a change from their own baselines

. Patients underwent a baseline echocardiogram, then received BiPAP for $1 \mathrm{~h}$ at a setting of $5 \mathrm{~cm}$ of water inspiratory pressure and $3 \mathrm{~cm}$ of expiratory pressure 
. After $1 \mathrm{~h}$ of BiPAP a second echocardiogram was performed. Finally, $1 \mathrm{~h}$ after BiPAP was discontinued, the echocardiogram was repeated a third time

\section{Results}

Symptoms, cardiac output, end diastolic volume, pulses, and respiratory rate all improved after one hour of BiPAP. This was confirmed by echocardiogram. Although this study addresses more acute respiratory effects, it raises interesting questions about long term BiPAP use. Given that $1 \mathrm{~h}$ post-BiPAP there was still some improved cardiac output and decreased end-diastolic volume, what would the residual effects be of longer term BiPAP use? If improvements were seen after $1 \mathrm{~h}$, what would the effect of overnight BiPAP be? Could overnight BiPAP decrease CHF symptoms during the day? Could BiPAP be used to treat $\mathrm{CHF}$ as well as sleep apnea?

\section{References}

1. Acosta B, Dibendetto R, Rahimi A: Hemodynamic effects of noninvasive bilevel positive airway pressure on patients with chronic congestive heart failure with systolic dysfunction. Chest. 2001, 1004-1009. 